\title{
Assessment of Prestress Force in Bridges Using Structural Dynamic Responses under Moving Vehicles
}

\author{
Hao Li, Zhongrong Lv, and Jike Liu \\ Department of Applied Mechanics and Engineering, Sun Yat-sen University, Guangzhou 510006, China \\ Correspondence should be addressed to Zhongrong Lv; lvzhr@mail.sysu.edu.cn
}

Received 1 July 2013; Revised 7 August 2013; Accepted 10 August 2013

Academic Editor: Zhiqiang Hu

Copyright ( 2013 Hao Li et al. This is an open access article distributed under the Creative Commons Attribution License, which permits unrestricted use, distribution, and reproduction in any medium, provided the original work is properly cited.

\begin{abstract}
This study carries out numerical simulations to identify the magnitude of prestress force in a highway bridge by making use of the dynamic responses from moving vehicular loads. The prestressed bridges are modeled using four-node isoparametric flat shell element taking into account the transverse shearing deformation in the finite element model. The vehicle is modeled as a multiple degrees-of-freedom system. An approach based on dynamic response sensitivity-based finite element model updating is proposed to identify the elemental prestress force. The identified results are obtained iteratively with the penalty function method with regularization from the measured structural dynamic responses. A single-span prestressed Tee beam and two-span prestressed box-girder bridge are studied as two numerical examples. The effects of road surface roughness, measurement noise, and speed of moving vehicle on the identification results are investigated. Studies indicate that the proposed method is efficient and robust for prestress force identification. Good identified results can be obtained from several measured acceleration responses.
\end{abstract}

\section{Introduction}

There are many researches in the literature which deal with the bridge vibration caused by the passing of vehicles or trains [1-11]. Akin and Mofid [1] proposed a combined analyticalnumerical method to determine the dynamic behavior of beams with a moving mass. Hwang and Nowak [2] developed the models for trucks, road surface, and the bridge, and the calculated static and dynamic deflections are obtained as a function of gross vehicle weight, span, and axle distance. Yang and Lin [3] and Yang and Yau [4] studied dynamic responses of vehicle-bridge systems with the finite element method. Law and Zhu [5] investigated the bridge dynamic responses due to road surface roughness and braking of vehicle. Yau [7] investigated the interaction response of a train running over a suspension bridge. Wang et al. [9] studied the nonlinear dynamic response of a long-span suspension bridge under running train and turbulent wind. These researches can be classified into the following categories: models of the vehicle, road surface roughness, bridge-vehicle interaction, the effect of vehicle braking, and so forth. In these studies, the parameters of the bridge and the vehicles are known and the dynamic responses of the bridge and/or the vehicle-bridge system can be obtained from forward analysis.
In this study, we try to identify the prestress force from the dynamic responses induced by the passing vehicles on top of the bridges. It is known that the prestress force is one of the most important parameters in prestressed concrete bridges to control the cracks in concrete, to reduce deflection of the structure, and to add strength to the prestressed members. Therefore, a substantial difference between the desired and the in-service prestress forces can result in severe serviceability and safety problems $[12,13]$. It is known that the loss of prestress force occurs due to the friction between the prestressing tendon and the surrounding concrete, creep, and shrinkage of the concrete, steel relaxation or damage of the prestress strands. Therefore, it is very important to estimate the real prestress level when the prestressed structures are in service.

Abraham et al. [13] tried to predict the loss of prestress force based on a damage index derived from the derivatives of mode shapes without success. Miyamoto et al. [14] studied the behavior of a beam with unbonded tendons, and a formula was proposed for the prediction of the modal frequency for a given prestress force with laboratory and field test verifications. Saiidi et al. [15] also reported a study on modal frequencies due to the prestress force with laboratory test results. Recently, Kim et al. [16] proposed an approach to 
identify the prestress loss in prestressed concrete beams using the modal information. Lu and Law [17] presented a method to identify the elemental prestress force using the structural dynamic responses.

In this paper, the dynamic behavior of the Tee beam bridge and the box-girder bridge is investigated using fournode isoparametric flat shell element; the transverse shearing deformation is taken into account in the finite element model. Then the coupling equation of motion of the bridge-vehicle system is established, and the dynamic responses of the system are obtained from numerical integration method. In the inverse analysis, we attempt to identify the elemental prestress force level making use of the dynamic responses induced by the passing vehicles. An approach based on dynamic response sensitivity-based finite element model updating is proposed to identify the prestress force. Two numerical examples are studied to illustrate the correctness of the proposed method. Some aspects such as the effects of road surface roughness, measurement noise, and speed of the moving vehicle on the identification results are investigated. Simulation studies indicate that the proposed method is efficient and robust, and good identified results can be obtained.

\section{Formulation}

2.1. Strain-Displacement Relationship. In this paper, the plat shell element is used to establish the finite element model of the bridge. This kind of element has five degrees-of-freedom for each node and can be obtained from superimposing the planar stress element on the plate bending element [18].

The strains of the flat shell include the inplane membrane strains $\varepsilon^{p}$, the curvature owing to the bending $\varepsilon^{b}$, and the transverse shearing strains $\varepsilon^{s}$.

For the inplane membrane strains

$$
\varepsilon^{p}=\left\{\begin{array}{c}
\varepsilon_{x} \\
\varepsilon_{y} \\
\gamma_{x y}
\end{array}\right\}=\left\{\begin{array}{c}
\frac{\partial u}{\partial x} \\
\frac{\partial v}{\partial y} \\
\frac{\partial v}{\partial x}+\frac{\partial u}{\partial y}
\end{array}\right\} .
$$

For bending strains

$$
\varepsilon^{b}=-z\left\{\begin{array}{c}
\kappa_{x} \\
\kappa_{y} \\
\kappa_{x y}
\end{array}\right\}=-z\left\{\begin{array}{c}
\frac{\partial \theta_{x}}{\partial x} \\
\frac{\partial \theta_{y}}{\partial y} \\
\frac{\partial \theta_{x}}{\partial y}+\frac{\partial \theta_{y}}{\partial x}
\end{array}\right\} .
$$

For transverse shearing strains

$$
\varepsilon^{s}=\left\{\begin{array}{l}
\gamma_{x z} \\
\gamma_{y z}
\end{array}\right\}=\left\{\begin{array}{l}
\frac{\partial w}{\partial x}-\theta_{x} \\
\frac{\partial w}{\partial y}-\theta_{y}
\end{array}\right\}
$$

The expressions for the strains-displacement matrices are deduced from (1)-(3) as

$$
\begin{gathered}
\mathcal{\varepsilon}^{p}=\sum_{i=1}^{N}\left[\begin{array}{cc}
N_{i, x}^{(m)} & \\
& N_{i, y}^{(m)} \\
N_{i, y}^{(m)} & N_{i, x}^{(m)}
\end{array}\right]\left\{\begin{array}{l}
u_{i} \\
v_{i}
\end{array}\right\}=\sum_{i=1}^{N} B_{i}^{m} a_{i}^{(m)}, \\
\varepsilon^{s}=\sum_{i=1}^{N}\left[\begin{array}{ccc}
N_{i, x}^{w} & -N_{i}^{\theta} & 0 \\
N_{i, y}^{w} & 0 & -N_{i}^{\theta}
\end{array}\right]\left\{\begin{array}{c}
w_{i} \\
\left(\theta_{x}\right)_{i} \\
\left(\theta_{y}\right)_{i}
\end{array}\right\}=\sum_{i=1}^{N} B_{i}^{s} a_{i}^{(s)}, \\
\varepsilon^{b}=\sum_{i=1}^{N}\left[\begin{array}{ccc}
0 & N_{i, x}^{\theta} & 0 \\
0 & 0 & N_{i, y}^{\theta} \\
0 & N_{i, y}^{\theta} & N_{i, x}^{\theta}
\end{array}\right]\left\{\begin{array}{c}
w_{i} \\
\left(\theta_{x}\right)_{i} \\
\left(\theta_{y}\right)_{i}
\end{array}\right\}=\sum_{i=1}^{N} B_{i}^{b} a_{i}^{(b)},
\end{gathered}
$$

where $N$ is the number of nodes of the element, $N_{i}^{(m)}, N_{i}^{(s)}$, and $N_{i}^{(b)}$ are the isoparametric shape functions of the plane stress, shear stress, and bending stress, respectively.

2.2. The Elemental Mass and Stiffness Matrices. The consistent elemental mass matrix can be expressed as

$$
m^{e}=\int_{A} \Theta^{T} \rho_{m} \Theta d A,
$$

where

$$
\begin{gathered}
\rho_{m}=\left[\begin{array}{cccccc}
\rho t & 0 & 0 & 0 & 0 & 0 \\
0 & \rho t & 0 & 0 & 0 & 0 \\
0 & 0 & \rho t & 0 & 0 & 0 \\
0 & 0 & 0 & \frac{\rho t^{3}}{12} & 0 & 0 \\
0 & 0 & 0 & 0 & \frac{\rho t^{3}}{12} & 0 \\
0 & 0 & 0 & 0 & 0 & 0
\end{array}\right], \\
\Theta=\left[\Theta_{1}, \Theta_{2}, \ldots, \Theta_{N}\right],
\end{gathered}
$$

in which

$$
\Theta_{i}=\left[\begin{array}{lllll}
N_{u i}^{(m)} & & & & \\
& N_{v i}^{(m)} & & & \\
& & N_{i}^{(w)} & & \\
& & & N_{i}^{\left(\theta_{x}\right)} & \\
& & & & N_{i}^{\left(\theta_{y}\right)}
\end{array}\right] .
$$

It is known that the global stiffness is singular or illconditioned because of the null diagonal terms due to the drilling degrees of freedom in the transformed elemental stiffness matrix. To solve this problem, in this paper, we artificially insert a rotational stiffness coefficient as it was done by Lee and Yhim [19]; the artificial stiffness for the drilling DOF is taken as $\gamma_{k}=10^{7}$ in this study. 


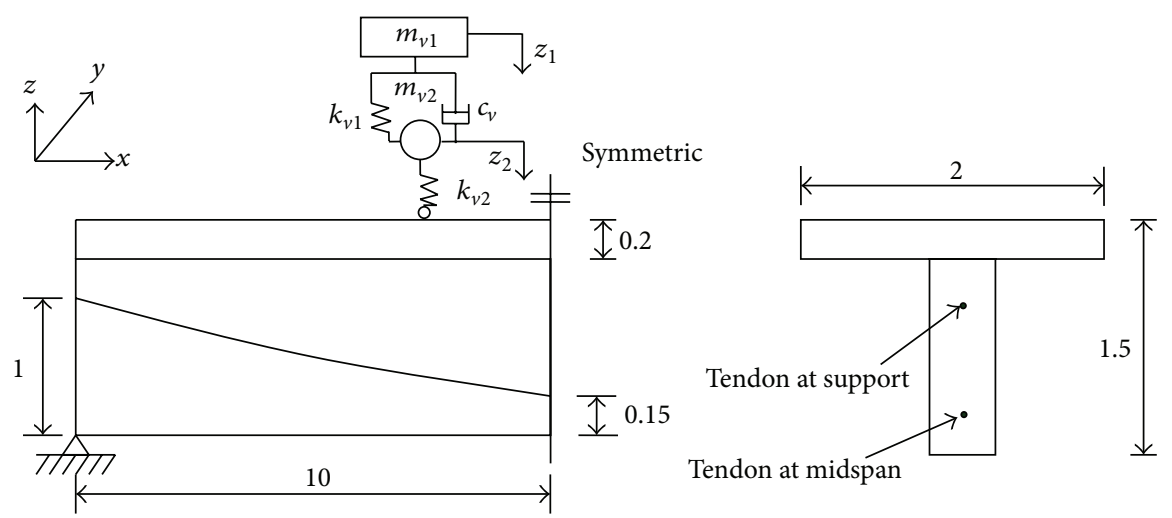

(a)

\begin{tabular}{|l|l|l|l|l|l|}
\hline 21 & 22 & 23 & $\ldots$ & 39 & 40 \\
\hline 1 & 2 & 3 & $\ldots$ & 19 & 20 \\
\hline
\end{tabular}

(b)

\begin{tabular}{|l|l|l|l|l|l|}
\hline 41 & 42 & 43 & $\ldots$ & 59 & 60 \\
\hline
\end{tabular}

(c)

Figure 1: (a) Vehicle models and the geometry of the simply supported Tee beam (dimension in meter). (b) Element number for the flange of the Tee beam. (c) Element number for the web of the Tee beam.

Elemental stiffness matrix of the concrete bridge is expressed as

$$
\begin{aligned}
K^{e}= & \int_{A}\left(B_{i}^{p}\right)^{T} D^{p} B_{j}^{p} d A+\int_{A}\left(B_{i}^{s}\right)^{T} D^{s} B_{j}^{s} d A \\
& +\int_{A}\left(B_{i}^{b}\right)^{T} D^{b} B_{j}^{b} d A \\
& +\int_{A} G_{i}^{T}\left[\begin{array}{cc}
T_{x 0}^{p} & 0 \\
0 & T_{y 0}^{p}
\end{array}\right] G_{j} d A,
\end{aligned}
$$

where $D^{p}, D^{s}$, and $D^{b}$ are the material property matrices for plane stress, shear stress, and bending stress:

$$
G_{i}=\left[\begin{array}{llllll}
N_{i, x}^{u} & N_{i, x}^{v} & N_{i, x}^{w} & 0 & 0 & 0 \\
N_{i, y}^{u} & N_{i, y}^{v} & N_{i, y}^{w} & 0 & 0 & 0
\end{array}\right]
$$

$T_{x 0}^{p}$ and $T_{y 0}^{p}$ are the two components of the prestress force in $x$ - and $y$-axis, respectively.

After assembling the elemental stiffness and mass matrices into system matrices, the equation of motion of the bridge structure can be written as

$$
M_{b} \ddot{d}+C_{b} \dot{d}+K_{b} d=H_{c} P_{\text {int }},
$$

where $M_{b}$ and $K_{b}$ are the system mass and stiffness matrices, respectively, $C_{b}$ is the damping matrix; in this study, Rayleigh damping model is used; that is, $C=\alpha_{1} M_{b}+\alpha_{2} K_{b}$, where $\alpha_{1}$ and $\alpha_{2}$ are two constants. $\ddot{d}, \dot{d}$ and $d$ are the acceleration velocity and displacement responses of the structure, respectively. $P_{\text {int }}$ is the interaction force between the bridge and the vehicle. $H_{c}$ is a matrix with zero entries except at the DOFs corresponding to the nodal displacements of the shell elements on which the load is acting.
2.3. Equation of Motion for the Vehicle-5-Parameter Vehicle Model. The five-parameter vehicle model of the two degreeof-freedom system shown in Figure 1 comprises five components: an upper mass $m_{v 1}$ of the suspension, a lower mass $m_{v 2}$ of the bogie and axle connected to the suspension damper $c_{v}$, and a suspension spring $k_{v 1}$, together with another spring $k_{v 2}$, which is used to represent the stiffness of the tyre. The equations of motion of the masses $m_{v 1}$ and $m_{v 2}$ are

$$
\begin{aligned}
m_{v 1} \ddot{z}_{1} & +c_{v}\left(\dot{z}_{1}-\dot{z}_{2}\right)+k_{v 1}\left(z_{1}-z_{2}\right)=0, \\
m_{v 2} \ddot{z}_{2}+ & c_{v}\left(\dot{z}_{2}-\dot{z}_{1}\right)+k_{v 1}\left(z_{2}-z_{1}\right) \\
& +k_{v 2}\left(z_{2}-(w(x, y, t)+r(x))\right)=0,
\end{aligned}
$$

where $\ddot{z}_{1}, \dot{z}_{1}$, and $z_{1}$ are the vertical acceleration, velocity, and displacement responses of the suspension mass of vehicle, respectively, and $\ddot{z}_{2}, \dot{z}_{2}$, and $z_{2}$ are the vertical acceleration, velocity, and displacement responses of the bogie and axle. $r(x)$ is the road surface roughness at the location of the tyre [20], which will be given in the next subsection. It should be pointed out that, in (12), the additional velocity and acceleration due to road surface roughness may be taken into account to determine the movement of the vehicle wheel as discussed by Chang et al. [21]. The interaction force $P_{\text {int }}$ between the bridge and the vehicle can be expressed as

$$
\begin{aligned}
P_{\text {int }} & =\left(m_{v 1}+m_{v 2}\right) g+k_{v 2}\left(z_{2}-(w(x, y, t)+r(x))\right) \\
& =\left(m_{v 1}+m_{v 2}\right) g-m_{v 1} \ddot{z}_{1}-m_{v 2} \ddot{z}_{2} .
\end{aligned}
$$


Equations (10), (11), and (12) can be combined in a compact form and the coupled vehicle-bridge equations of motion can be written as

$$
\begin{aligned}
& {\left[\begin{array}{ccc}
M_{b} & H_{c} m_{v 1} & H_{c} m_{v 2} \\
0 & m_{v 1} & 0 \\
0 & 0 & m_{v 2}
\end{array}\right]\left\{\begin{array}{c}
\ddot{d} \\
\ddot{z}_{1} \\
\ddot{z}_{2}
\end{array}\right\}} \\
& +\left[\begin{array}{ccc}
C_{b} & 0 & 0 \\
0 & c_{v} & 0 \\
0 & 0 & c_{v}
\end{array}\right]\left\{\begin{array}{l}
\dot{d} \\
\dot{z}_{1} \\
\dot{z}_{2}
\end{array}\right\} \\
& +\left[\begin{array}{ccc}
K_{b} & 0 & 0 \\
0 & k_{v 1} & -k_{v 1} \\
-H_{c}^{T} k_{v 2} & -k_{v 1} & k_{v 1}+k_{v 2}
\end{array}\right]\left\{\begin{array}{l}
d \\
z_{1} \\
z_{2}
\end{array}\right\} \\
& =\left\{\begin{array}{c}
H_{c}\left(m_{v 1}+m_{v 2}\right) g \\
0 \\
k_{v 2} r(x)
\end{array}\right\},
\end{aligned}
$$

Let

$$
\begin{gathered}
\bar{M}_{s}=\left[\begin{array}{ccc}
M_{b} & H_{c} m_{v 1} & H_{c} m_{v 2} \\
0 & m_{v 1} & 0 \\
0 & 0 & m_{v 2}
\end{array}\right], \quad \bar{C}_{s}=\left[\begin{array}{ccc}
C_{b} & 0 & 0 \\
0 & c_{v} & 0 \\
0 & 0 & c_{v}
\end{array}\right], \\
\bar{K}_{s}=\left[\begin{array}{ccc}
K_{b} & 0 & 0 \\
0 & k_{v 1} & -k_{v 1} \\
-H_{c}^{T} k_{v 2} & -k_{v 1} & k_{v 1}+k_{v 2}
\end{array}\right], \quad R_{s}=\left\{\begin{array}{l}
d \\
z_{1} \\
z_{2}
\end{array}\right\}, \\
\bar{P}(t)=\left\{\begin{array}{c}
H_{c}\left(m_{v 1}+m_{v 2}\right) g \\
0 \\
k_{v 2} r(x)
\end{array}\right\} .
\end{gathered}
$$

Equation (14) can be rewritten as

$$
\bar{M}_{s} \ddot{R}_{s}+\bar{C}_{s} \dot{R}_{s}+\bar{K}_{s} R_{s}=\bar{P}(t) .
$$

The dynamic responses of the bridge and vehicle can be obtained from a step-by-step solution using the state space method [22].

2.4. Road Surface Roughness. The randomness of the road surface roughness of the bridge can be represented with a periodic modulated random process. It is specified by its power spectral density function (PSD) as [23]

$$
S_{r}\left(\omega_{s}\right)=A_{r}\left(\frac{\omega_{s}}{\omega_{s 0}}\right)^{-2}
$$

where $A_{r}$ is the roughness coefficient in $\mathrm{m}^{2} /$ cycle $/ \mathrm{m}, \omega_{s}$ is the spatial frequency in cycle $/ \mathrm{m}, \omega_{s}$ is the discontinuity frequency equal to $1 / 2 \pi$ (cycle $/ \mathrm{m}$ ).

The road surface roughness function $r(x)$ can be generated from (17) using the FFT algorithm [23], which is given by

$$
r(x)=\sum_{i=1}^{N}\left(4 A_{r}\left(\frac{2 \pi i}{L_{c} \omega_{s 0}}\right)^{-2} \frac{2 \pi}{L_{c}}\right)^{1 / 2} \cos \left(\omega_{s i} x-\theta_{i}\right),
$$

where $\omega_{s i}=i \Delta \omega_{s}$, with $\Delta \omega_{s}=2 \pi / L_{c}$, in which $L_{c}$ is twice the length of the bridge, $\theta_{i}$ is a random number distributed uniformly between 0 and $2 \pi$.

2.5. Dynamic Response Sensitivity with Respect to Prestress Force. Differentiating both sides of (16) with respect to the prestress force of the $i$ th element, we have

$$
\bar{M}_{s} \frac{\partial \ddot{R}_{s}}{\partial T_{i}}+\bar{C}_{s} \frac{\partial \dot{R}_{s}}{\partial T_{i}}+\bar{K}_{s} \frac{\partial R_{s}}{\partial T_{i}}+\alpha_{2} \frac{\partial \bar{K}_{s}}{\partial T_{i}} R_{s}+\frac{\partial \bar{K}_{s}}{\partial T_{i}} R_{s}=0 .
$$

Let $D=\partial R_{s} / \partial T_{i}, \dot{D}=\partial \dot{R}_{s} / \partial T_{i}$, and $\ddot{D}=\partial \ddot{R}_{s} / \partial T_{i}$; since the global matrix $\bar{K}_{s}$ is the function of the prestress force $T$, the partial derivative $\partial \bar{K}_{s} / \partial T_{i}$ can be obtained directly. The fourth and fifth terms in (19) on the left-hand side can be removed to the right-hand side as the "input force." Equation (19) can be rewritten as

$$
\bar{M}_{s} \ddot{D}+\bar{C}_{s} \dot{D}+\bar{K}_{s} D=-\alpha_{2} \frac{\partial \bar{K}_{s}}{\partial T_{i}} \dot{R}_{s}-\frac{\partial \bar{K}_{s}}{\partial T_{i}} R_{s} .
$$

Similarly, the dynamic response sensitivities $D, \dot{D} \ddot{D}$ can be obtained from (20).

2.6. Identification of Prestress Force from Measured Dynamic Response. The identification problem is to find the vector of prestress force $\{T\}$ such that the calculated responses $R_{s}$ best match the measured responses $\widehat{R}$; that is,

$$
[Q]\left\{R_{s}\right\}=\{\widehat{R}\},
$$

where the selection matrix $[Q]$ is a constant matrix with elements of zeros or ones, which maps the degrees of freedom of the system to the measured degrees of freedom. $\left\{R_{s}\right\}$ and $\{\widehat{R}\}$ are the vectors of calculated and measured dynamic responses of the system, respectively. The inverse problem is to minimize the error between the calculated and measured responses as

$$
\{\delta R\}=\{\widehat{R}\}-[Q]\left\{R_{s}\right\}=\{\widehat{R}\}-\left\{R_{\text {cal }}\right\} .
$$

As we have no idea of the magnitude of the prestress force, the initial value for the elemental prestress force is set as a null vector. The corresponding response $R_{s}^{0}$ and the response sensitivity matrix $S^{0}$ are obtained from (16) and (20) with superscript " 0 " denoting the initial set of values.

At the $j$ th iteration, the difference between the measured and calculated system responses can be expressed as

$$
\Delta R^{j}=\widehat{R}-R_{\text {cal }}^{j}, \quad(j=0,1,2, \ldots) .
$$

Using the penalty function method [24], the vector of the prestress force increment, $\Delta T^{j}$, can be obtained from the following equation:

$$
\left[\bar{S}^{j}\right]\left\{\Delta T^{j}\right\}=\left\{\Delta R^{j}\right\}
$$


where $\left[\bar{S}^{j}\right]$ is a $n t \times N$ matrix selected from the sensitivity matrix $\left[S^{j}\right] . N$ is the number of unknown of prestress force; $n t$ is the number of measured data points. It is noted that $n t$ should be greater than $N$ to make sure that the equation is over-determined. Equation (24) can be solved by the damped least-squares method [25] with bounds to the solution

$$
\left\{\Delta T^{j}\right\}=\left(\left[\bar{S}^{j}\right]^{T}\left[\bar{S}^{j}\right]+\lambda I\right)^{-1}\left[\bar{S}^{j}\right]^{T}\left\{\Delta R^{j}\right\},
$$

where $\lambda$ is the nonnegative damping (regularization) coefficient governing the participation of least-squares error in the solution. The solution of (24) is equivalent to minimize the function

$$
J\left(\left\{\Delta T^{i}\right\}, \lambda\right)=\left\|\left[\bar{S}^{j}\right]\left\{\Delta R^{j}\right\}-\left\{\Delta T^{j}\right\}\right\|^{2}+\lambda\left\|\left\{\Delta T^{j}\right\}\right\|^{2}
$$

with the second term in (26) providing bounds to the solution. When the parameter $\lambda$ approaches to zero, the estimated vector $\left\{\Delta T^{j}\right\}$ approaches to the solution obtained from the simple least-squares method.

The updated prestress force $\left\{T^{j+1}\right\}=\left\{T^{j}\right\}+\left\{\Delta T^{j}\right\}(j=$ $0,1,2, \ldots)$ is calculated in the next iteration, and the dynamic response $R^{j+1}$ and response sensitivity $S^{j+1}$ are also recalculated. The convergence is considered achieved when the following criterion is met:

$$
\frac{\left\|\left\{T^{k+1}\right\}-\left\{T^{k}\right\}\right\|}{\left\|\left\{T^{k}\right\}\right\|} \leq \text { tolerance, }
$$

where $k$ denotes the $k$ th iteration. The tolerance is taken as $1 \times 10^{-7}$ in this study.

The relative error in identified results in each element is defined as

$$
\mathrm{RE}=\frac{\left(T_{i}\right)_{\text {identified }}-\left(T_{i}\right)_{\text {true }}}{\left(T_{i}\right)_{\text {true }}} \times 100 \%, \quad(i=1,2, \ldots, N) .
$$

\section{Numerical Simulations}

3.1. A Prestressed Tee Beam. The prestressed Tee beam studied by Figueiras and Póvoas [26] was used as the first numerical example in this paper. The beam is simply supported and prestressed with a parabolic tendon. The geometry of the beam is shown in Figure 1(a). The mechanical properties of the concrete are Young's modulus $E_{c}=3.4 \times 10^{10} \mathrm{~Pa}$, mass density $\rho_{c}=2800 \mathrm{~kg} / \mathrm{m}^{3}$, and Poisson ratio $v=0.18$. The mechanical properties of the prestressing tendon are Young's modulus $E_{p}=210 \mathrm{GPa}$, mass density $\rho_{p}=7800 \mathrm{~kg} / \mathrm{m}^{3}$. The magnitude of the prestress force is $3 \mathrm{MN}$, and the prestressing tendon is assumed to be perfectly bonded, and no prestress loss is taken into account.

In the finite element of the beam, the flange is discretized into two 4-node isoparametric flat shell elements in the transverse direction and 20 elements in the longitudinal direction. The web is discretized into 20 elements in the longitudinal direction. Figures 1(b) and 1(c) show the finite element
TABLE 1: Identified results for different road surface roughness.

\begin{tabular}{lcccc}
\hline & \multicolumn{4}{c}{ Road surface roughness } \\
& Class A & Class B & Class C & Class D \\
\hline Max error (\%) & 0.01 & 0.02 & 0.02 & 0.05 \\
Iteration number & 12 & 12 & 13 & 18 \\
$\lambda_{\text {optimal }}$ & $1.21 \times 10^{-9}$ & $1.23 \times 10^{-9}$ & $1.30 \times 10^{-9}$ & $1.49 \times 10^{-9}$ \\
\hline
\end{tabular}

number sequence of Tee beam. From the free vibration analysis, the first nine natural frequencies of the prestressed beam are $6.30,7.441,8.268,21.545,21.923,24.243,35.075$, 36.847 , and $47.075 \mathrm{~Hz}$, respectively. The modal damping ratio is taken as 0.01 for the first two modes to obtain the two coefficients in Rayleigh damping.

The parameters of the five-parameter vehicle model are $m_{v 1}=3.6 \times 10^{3} \mathrm{~kg}, m_{v 2}=0.25 \times 10^{3} \mathrm{~kg}, c_{v}=1.0 \times 10^{3} \mathrm{Ns} / \mathrm{m}$, $k_{v 1}=6.0 \times 10^{5} \mathrm{~N} / \mathrm{m}$, and $k_{v 2}=8.5 \times 10^{5} \mathrm{~N} / \mathrm{m}$. The traveling speed of the vehicle is assumed to be $20 \mathrm{~m} / \mathrm{s}$. Classes A to $D$ road surface roughness is included. Figure 2 gives a comparison on the displacement responses of the vehicle and that at the middle point of the flange for different road roughness coefficients. From this figure one can find that the road roughness coefficient has significant effect on the responses for both the bridge and the vehicle.

To simulate the effect of measurement noise, a normally distributed random error with zero mean and a unit standard deviation is added to the calculated acceleration as

$$
\widehat{\ddot{R}}=\ddot{R}_{\text {cal }}+E_{p} \times N_{\text {oise }} \times \operatorname{var}\left(\ddot{R}_{\text {cal }}\right),
$$

where $\widehat{\ddot{R}}$ is the vectors of measured structural acceleration response; $E_{p}$ is the noise level; $N_{\text {oise }}$ is a standard normal distribution vector with zero mean and unit standard deviation; $\operatorname{var}\left(\ddot{R}_{\text {cal }}\right)$ is the variance of the time history.

Study Case 1: Effect of Different Road Surface Roughness. In this case, we make use of the noise-free acceleration response of the bridge induced by the vehicle passing on top of the bridge at a speed of $10 \mathrm{~m} / \mathrm{s}$ to identify the prestress force with different road surface roughness. The sampling rate is $100 \mathrm{~Hz}$ which is high enough to include the first nine frequencies of the bridge, and the measurement time duration is 2 seconds in the identification. Three acceleration measurements located at $L / 4, L / 2$, and $3 L / 4$ of the bridge at the bottom of the web are used for the prestress force identification. The maximum errors in identified result for each road surface roughness are listed in Table 1. One can find the prestress force in each element has been identified with very high accuracy for each road surface roughness. Figure 3 shows the identified results for road roughness Class B.

Study Case 2: Effect of Different Vehicle Speed. Three different vehicle speeds are studied, that is, $10 \mathrm{~m} / \mathrm{s}, 20 \mathrm{~m} / \mathrm{s}$, and $40 \mathrm{~m} / \mathrm{s}$, and the corresponding measurement time duration is 2 seconds. The sampling rate is $100 \mathrm{~Hz}$. The same vehicle and measurement locations as Study Case 1 are used. Class B 




(a)

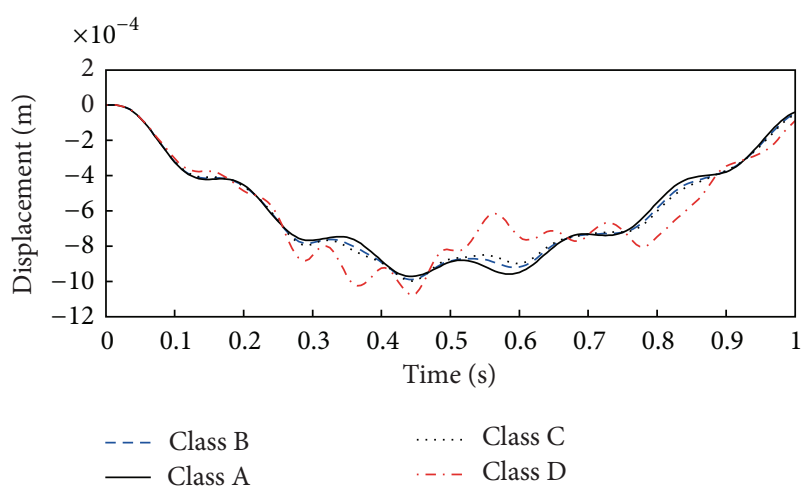

(b)

Figure 2: Effect of road roughness on the displacement responses of the vehicle and the beam ((a) the vehicle; (b) middle span point of the beam).

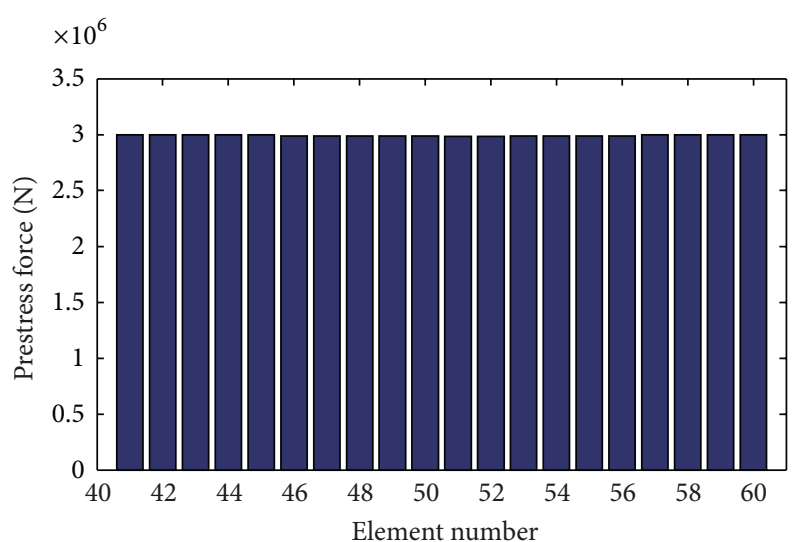

FIGURE 3: Identified elemental prestress force (without noise).



FIGURE 4: Identified elemental prestress force (with 10\% noise).

road surface roughness is assumed. The maximum errors in identified results for each speed are summarized in Table 2. This table indicates that different vehicle speed has little effect on the identified results.
TABLE 2: Identified results for different vehicle speed.

\begin{tabular}{lccc}
\hline & \multicolumn{3}{c}{ Vehicle speed (m/s) } \\
& 10 & 20 & 40 \\
\hline Max error (\%) & 0.02 & 0.02 & 0.02 \\
Iteration number & 12 & 13 & 13 \\
$\lambda_{\text {optimal }}$ & $1.23 \times 10^{-9}$ & $1.24 \times 10^{-9}$ & $1.24 \times 10^{-9}$ \\
\hline \multicolumn{4}{c}{ TABLE 3: Identified results for different noise level. } \\
& $1 \%$ & Measurement noise \\
& 1.65 & $5 \%$ & $10 \%$ \\
\hline Max error (\%) & 14 & 2.24 & 4.11 \\
Iteration number & $5.63 \times 10^{-9}$ & $9.12 \times 10^{-9}$ & $1.04 \times 10^{-8}$ \\
$\lambda_{\text {optimal }}$ & \multicolumn{3}{c}{}
\end{tabular}

Study Case 3: Effect of Different Measurement Noise. The same three acceleration measurements as Study Case 1 contaminated with different noise levels, that is, $1 \%, 5 \%$, and $10 \%$, are studied. The maximum errors in identified result for each noise level are listed in Table 3. From this table, one can find that the effect of measurement noise on the identified results is not significant. Even for $10 \%$ noise level, the maximum identification error is $4.11 \%$. This indicates the identified results are insensitive to the measurement noise. Figure 4 shows the identified results in which the noise level is $10 \%$.

3.2. A Prestressed Box-Girder Bridge. A two-span prestressed box-girder bridge is studied in this numerical example as shown in Figure 5(a). The dimension of the bridge is shown in Figure 5(a). Physical parameters of the bridge are Young's modulus $E=3.4 \times 10^{10} \mathrm{~Pa}$, mass density $\rho=2.5 \times 10^{3} \mathrm{~kg} / \mathrm{m}^{3}$. The bridge is assumed to be jacked at both ends and the magnitude of the prestress force at the jack is assumed to be $T=4 \mathrm{MN}$ in the left $\mathrm{rib}$ and $T=6 \mathrm{MN}$ in the right rib. The layout of prestressing tendon is parabolic. The prestress loss is 


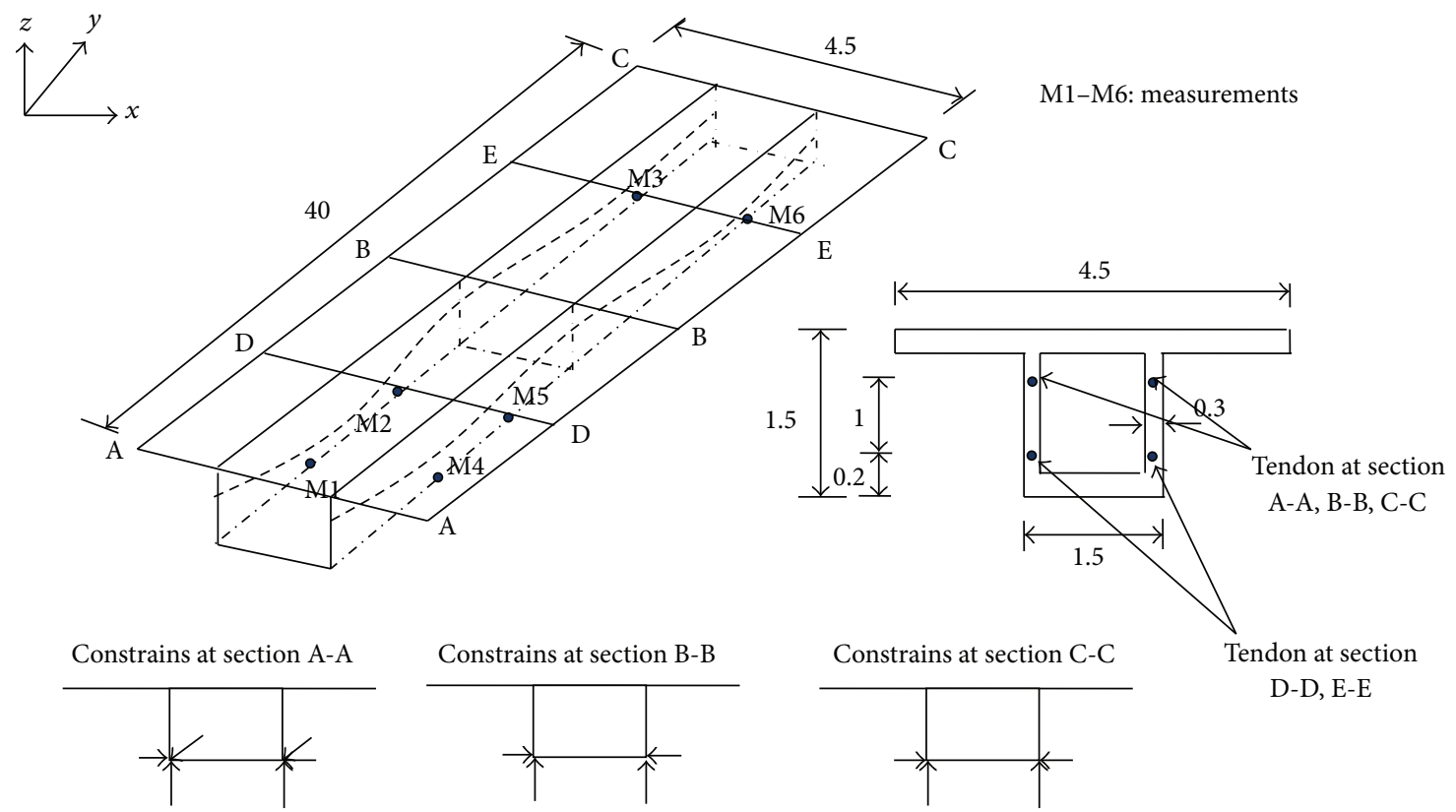

(a)

\begin{tabular}{|c|c|c|c|c|c|}
\hline 41 & 42 & 43 & $\ldots$ & 59 & 60 \\
\hline 21 & 22 & 23 & $\ldots$ & 39 & 40 \\
\hline 1 & 2 & 3 & & 19 & 20 \\
\hline
\end{tabular}

(b)

\begin{tabular}{|l|l|l|l|l|l|}
\hline 81 & 82 & 83 & $\ldots$ & 99 & 100 \\
\hline
\end{tabular}

(d)

\begin{tabular}{|l|l|l|l|l|l|}
\hline 61 & 62 & 63 & $\ldots$ & 79 & 80 \\
\hline
\end{tabular}

(c)

\begin{tabular}{|l|l|l|l|l|l|}
\hline 101 & 102 & 103 & $\ldots$ & 119 & 120 \\
\hline
\end{tabular}

(e)

FIgURE 5: (a) Two-span prestressed box-girder bridge (dimension in meter). (b) Element number for the upper plate of the box-girder bridge. (c) Element number for the lower plate of the box-girder bridge. (d) Element number for the left rib of the box-girder bridge. (e) Element number for the right rib of the box-girder bridge.

taken into account. Table 4 shows the prestress force in each of the 20 elements in the rib.

In the finite element of the bridge, the upper plate of bridge is discretized into three 4-node isoparametric flat shell elements in the transverse direction and 20 elements in the longitudinal direction. The bottom plate of the bridge is discretized into 1 element in the transverse direction and 20 elements in the longitudinal direction. The rib is discretized into 20 elements in the longitudinal direction. Figures 5(b)5(e) show the finite element number sequence of the bridge. The first ten natural frequencies of the prestressed beam are $7.942,11.510,13.369,17.086,18.773,23.529,23.604,29.427$, 33.345 , and $34.134 \mathrm{~Hz}$, respectively. The modal damping ratio is taken as 0.01 for the first two modes to calculate the two coefficients in Rayleigh damping.

Study Case 4: Identification of Different Distributions of Prestress Force. The traveling speed of the vehicle is $20 \mathrm{~m} / \mathrm{s}$, which moves in the global $y$ direction on the top of the left rib. The sampling rate is $100 \mathrm{~Hz}$. Class B road surface is adopted. Six acceleration measurements M1-M6 as shown in Figure 5(a) are used for prestress force identification. The identified results converge to the true values after 15 iterations with a maximum relative identified error of $0.008 \%$ at element 91. The optimal regularization parameter $\lambda_{\text {opt }}$ is found to be $2.24 \times 10^{-12}$. Figure 6 shows the identified results.

Study Case 5: Effect of Measurement Noise. The effect of measurement noise on the identified results is studied. Case 5 is restudied, but it is assumed the "measured" acceleration responses are contaminated with noise. Ten percent noise level is studied. The identified results converged after 27 iterations as shown in Figure 7 with a maximum identified error $3.58 \%$ at element 92 . The optimal regularization parameter $\lambda_{\text {opt }}$ is found to be $3.28 \times 10^{-12}$. 
TABLE 4: Magnitude of prestress force in each element.

\begin{tabular}{|c|c|}
\hline Element number & Prestress $(\mathrm{MN})$ \\
\hline 81 & 4.0 \\
\hline 82 & 3.88 \\
\hline 83 & 3.76 \\
\hline 84 & 3.64 \\
\hline 85 & 3.52 \\
\hline 86 & 3.40 \\
\hline 87 & 3.28 \\
\hline 88 & 3.12 \\
\hline 89 & 2.96 \\
\hline 90 & 2.8 \\
\hline 91 & 2.8 \\
\hline 92 & 2.96 \\
\hline 93 & 3.12 \\
\hline 94 & 3.28 \\
\hline 95 & 3.40 \\
\hline 96 & 3.52 \\
\hline 97 & 3.64 \\
\hline 98 & 3.76 \\
\hline 99 & 3.88 \\
\hline 100 & 4.0 \\
\hline 101 & 6.0 \\
\hline 102 & 5.82 \\
\hline 103 & 5.64 \\
\hline 104 & 5.46 \\
\hline 105 & 5.28 \\
\hline 106 & 5.10 \\
\hline 107 & 4.92 \\
\hline 108 & 4.68 \\
\hline 109 & 4.44 \\
\hline 110 & 4.20 \\
\hline 111 & 4.20 \\
\hline 112 & 4.44 \\
\hline 113 & 4.68 \\
\hline 114 & 4.92 \\
\hline 115 & 5.10 \\
\hline 116 & 5.28 \\
\hline 117 & 5.46 \\
\hline 118 & 5.64 \\
\hline 119 & 5.82 \\
\hline 120 & 6.0 \\
\hline
\end{tabular}

\section{Conclusions}

An approach making use of the dynamic responses of the bridge under moving vehicular load is proposed to identify the prestress force in the bridge. Four-node isoparametric flat shell element with the transverse shearing deformation is used to model the prestressed bridges. And the equation of motion of the bridge-vehicle system is established. The prestress forces are identified iteratively from a dynamic response sensitivity analysis based model updating using the
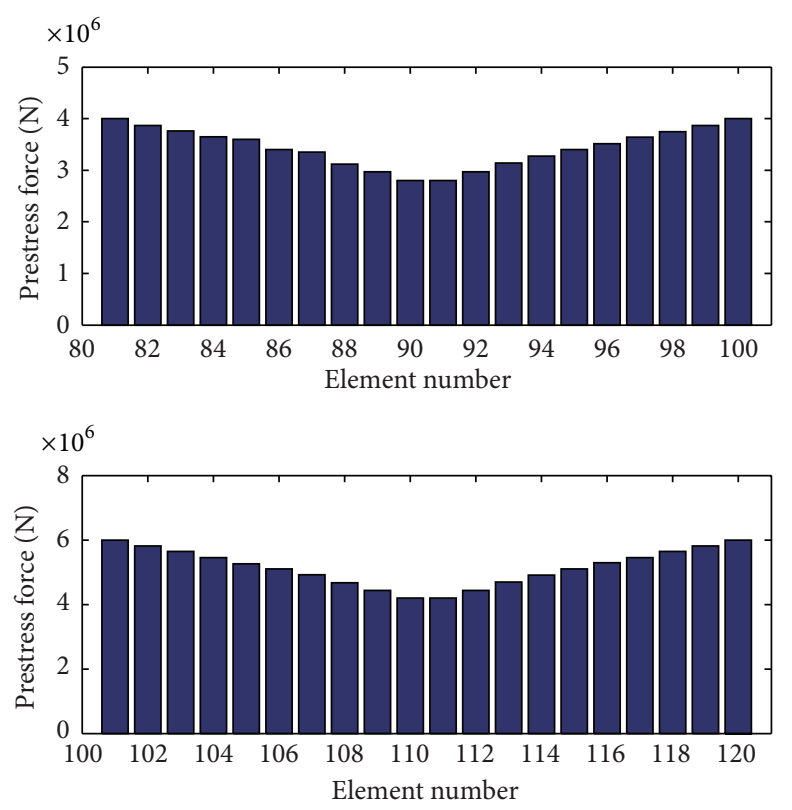

FIGURE 6: Identification of distributed prestress force in box-girder bridge (noise free).
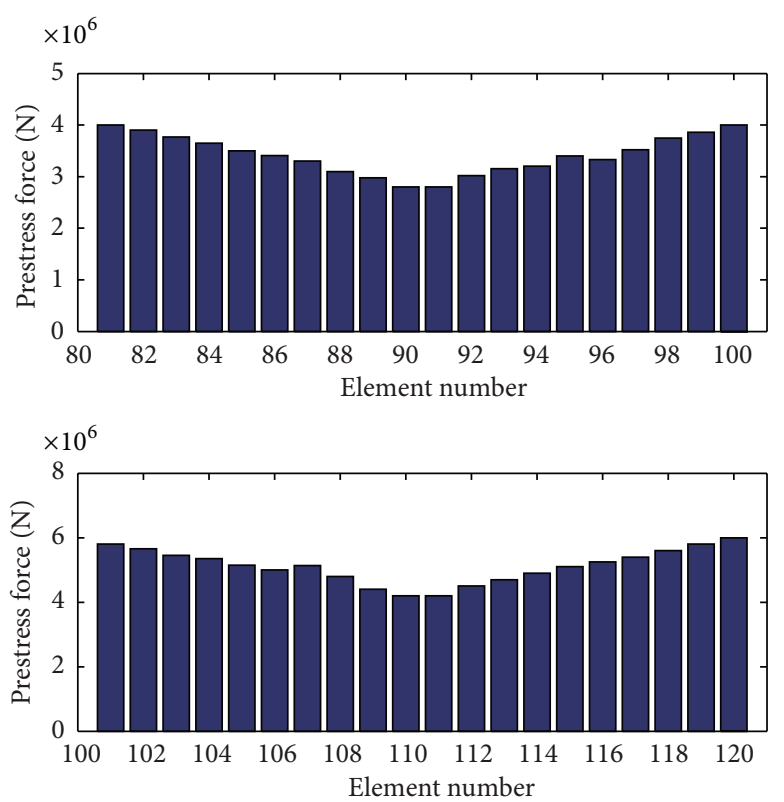

FIGURE 7: Identification of distributed prestress force in box-girder bridge (10\% noise).

measured dynamic responses of the bridge. Two numerical simulations indicate that the proposed method is correct and efficient for prestress force identification. Study shows that the speed of the moving vehicle has little effect on the identified results. Studies also show that artificial measurement noise does not have significant effect on the identified results, but larger identified error is observed under a weak road condition. 


\section{Acknowledgments}

This work is supported by the National Natural Science Foundation of China (11172333, 11272361), the Fundamental Research Funds for the Central Universities (13lgzd06), and the General Financial Grant from the China Postdoctoral Science Foundation (2013M531893). Such financial aids are gratefully acknowledged.

\section{References}

[1] J. E. Akin and M. Mofid, "Numerical solution for response of beams with moving mass," Journal of Structural Engineering, vol. 115, no. 1, pp. 120-131, 1989.

[2] E. S. Hwang and A. S. Nowak, "Simulation of dynamic load for bridges," Journal of Structural Engineering, vol. 117, no. 5, pp. 1413-1434, 1991.

[3] Y. B. Yang and B. H. Lin, "Vehicle-bridge interaction analysis by dynamic condensation method," Journal of Structural Engineering, vol. 121, no. 11, pp. 1636-1643, 1995.

[4] Y. B. Yang and J. D. Yau, "Vehicle-bridge interaction element for dynamic analysis," Journal of Structural Engineering, vol. 123, no. 11, pp. 1512-1518, 1997.

[5] S. S. Law and X. Q. Zhu, "Bridge dynamic responses due to road surface roughness and braking of vehicle," Journal of Sound and Vibration, vol. 282, no. 3-5, pp. 805-830, 2005.

[6] L. T. Stavridis, "A simplified analysis of the behavior of suspension bridges under live load," Structural Engineering and Mechanics, vol. 30, no. 5, pp. 559-576, 2008.

[7] J. D. Yau, "Vehicle/bridge interactions of a rail suspension bridge considering support movements," Interaction and Multiscale Mechanics, vol. 2, no. 3, pp. 35-48, 2009.

[8] K. C. Chang, F. B. Wu, and Y. B. Yang, "Effect of road surface roughness on indirect approach for measuring bridge frequencies from a passing vehicle," Interaction and Multiscale Mechanics, vol. 3, no. 4, pp. 1-16, 2010.

[9] S. Q. Wang, H. Xia, W. W. Guo, and N. Zhang, "Nonlinear dynamic response analysis of a long-span suspension bridge under running train and turbulent wind," Interaction and Multiscale Mechanics, vol. 3, no. 4, pp. 17-36, 2010.

[10] X. Z. Li and Y. Zhu, "Stochastic space vibration analysis of a train-bridge coupling system," Interaction and Multiscale Mechanics, vol. 3, no. 4, pp. 55-71, 2010.

[11] J. R. Yang, J. Z. Li, and Y. H. Chen, "Vibration analysis of CFST tied-arch bridge due to moving vehicles," Interaction and Multiscale Mechanics, vol. 3, no. 4, pp. 109-121, 2010.

[12] B. O. Aalami, "Structural modeling of posttensioned members," Journal of Structural Engineering, vol. 126, no. 2, pp. 157-162, 2000.

[13] M. A. Abraham, S. Y. Park, and N. Stubbs, "Loss of prestress prediction based on nondestructive damage location algorithms," in Proceedings of the Smart Structures and Materials: Smart Systems for Bridges, Structures, and Highways, pp. 60-67, International Society for Optics and Photonics, March 1995.

[14] A. Miyamoto, K. Tei, H. Nakamura, and J. W. Bull, "Behavior of prestressed beam strengthened with external tendons," Journal of Structural Engineering, vol. 126, no. 9, pp. 1033-1044, 2000.

[15] M. Saiidi, B. Douglas, and S. Feng, "Prestress force effect on vibration frequency of concrete bridges," Journal of Structural Engineering, vol. 120, no. 7, pp. 2233-2241, 1994.
[16] J. T. Kim, C. B. Yun, Y. S. Ryu, and H. M. Cho, "Identification of prestress-loss in PSC beams using modal information," Structural Engineering and Mechanics, vol. 17, no. 3-4, pp. 467482, 2004.

[17] Z. R. Lu and S. S. Law, "Identification of prestress force from measured structural responses," Mechanical Systems and Signal Processing, vol. 20, no. 8, pp. 2186-2199, 2006.

[18] K. J. Bathe, Finite Element Procedures in Engineering Analysis, Prentice Hall, Upper Saddle River, NJ, USA, 1996.

[19] S. Y. Lee and S. S. Yhim, "Dynamic behavior of long-span box girder bridges subjected to moving loads: numerical analysis and experimental verification," International Journal of Solids and Structures, vol. 42, no. 18-19, pp. 5021-5035, 2005.

[20] ISO 8608: Mechanical Vibration-Road Surface profilesReporting of Measured Data, 1995.

[21] K. C. Chang, F. B. Wu, and Y. B. Yang, "Disk model for wheels moving over highway bridges with rough surfaces," Journal of Sound and Vibration, vol. 330, no. 20, pp. 4930-4944, 2011.

[22] J. N. Juang, Applied System Identification, Prentice-Hall, Upper Saddle River, NJ, USA, 1994.

[23] K. Henchi, M. Fafard, M. Talbot, and G. Dhatt, "An efficient algorithm for dynamic analysis of bridges under moving vehicles using a coupled modal and physical components approach," Journal of Sound and Vibration, vol. 212, no. 4, pp. 663-683, 1998.

[24] M. I. Friswell and J. E. Mottershead, Finite Element Model Updating in Structural Dynamics, vol. 38, Kluwer Academic Publishers, Dordrecht, The Netherlands, 1995.

[25] A. N. Tihonov, "On the solution of ill-posed problems and the method of regularization," Doklady Akademii Nauk SSSR, vol. 151, pp. 501-504, 1963.

[26] J. A. Figueiras and R. H. C. F. Póvoas, "Modelling of prestress in non-linear analysis of concrete structures," Computers and Structures, vol. 53, no. 1, pp. 173-187, 1994. 




Advances in

Operations Research

mansans

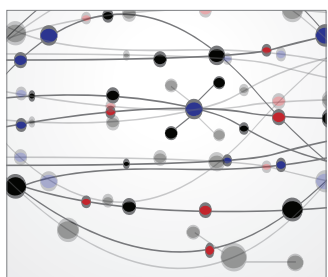

The Scientific World Journal
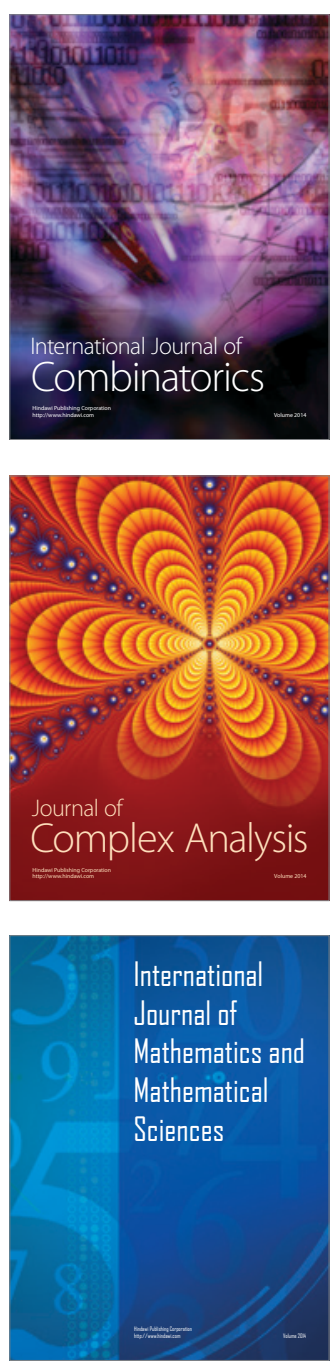
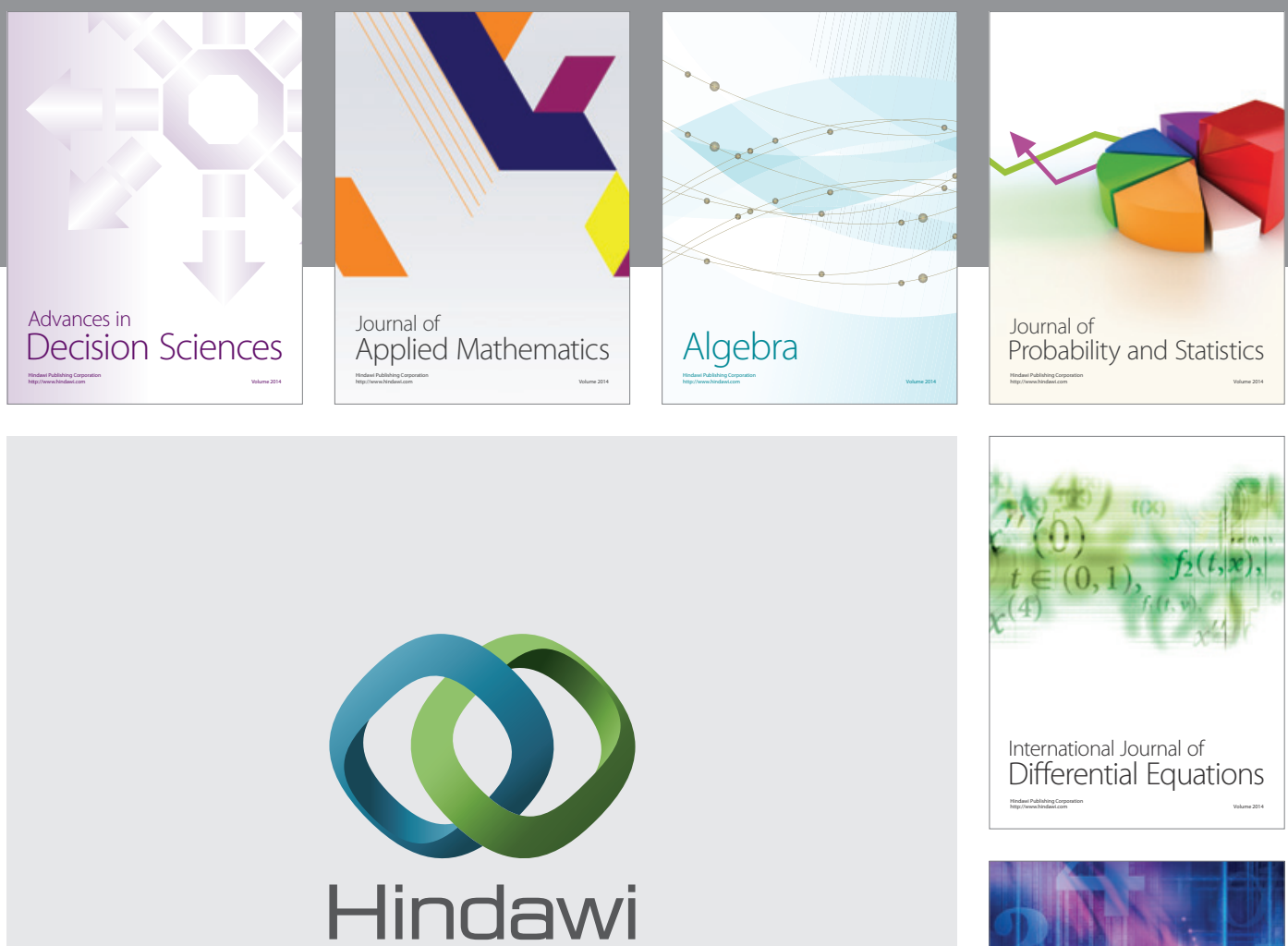

Submit your manuscripts at http://www.hindawi.com
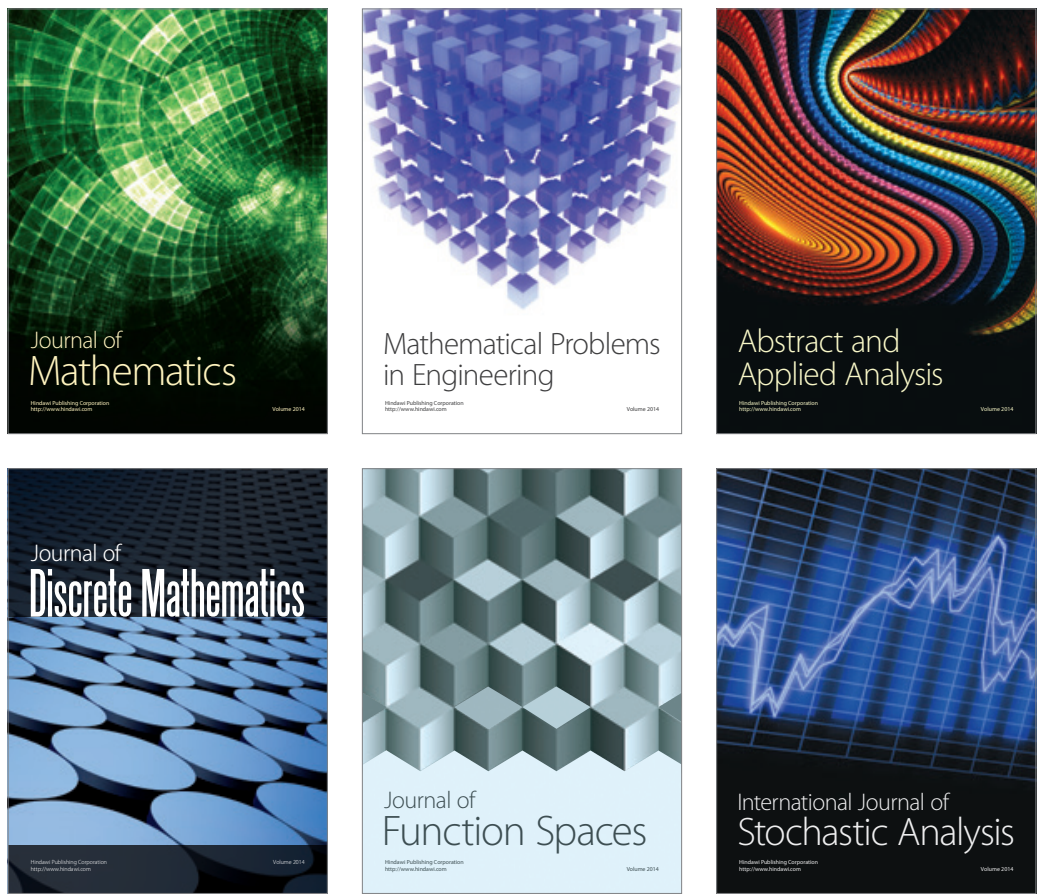

Journal of

Function Spaces

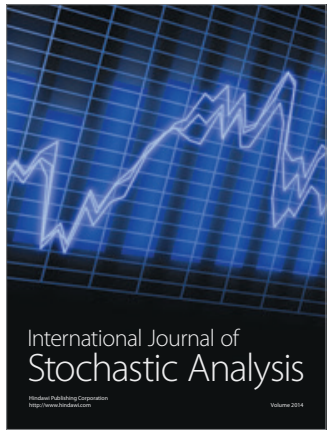

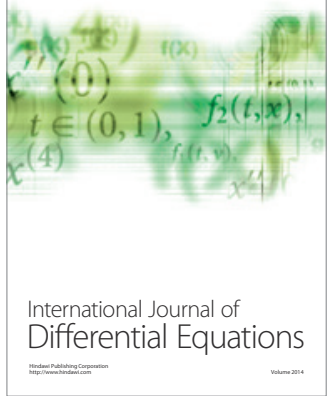
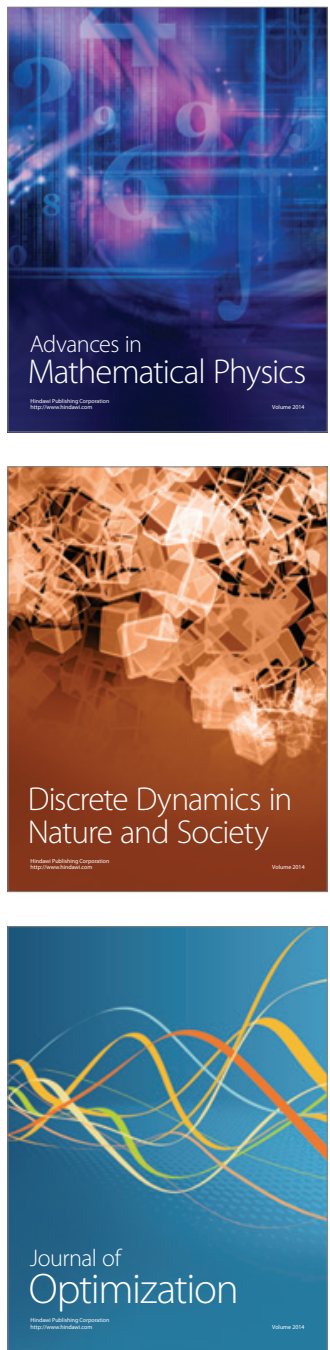